\title{
QUALIDADE FISIOLÓGICA DE SEMENTE DE MAMÃO EM FUNÇÃO DA SECAGEM E DO ARMAZENAMENTO ${ }^{1}$
}

\author{
PEDRO AMORIM BERBERT ${ }^{2}$, VINICIUS DE OLIVEIRA CARLESSO ${ }^{3}$, ROBERTO FERREIRA DA SILVA $^{4}$, EDUARDO \\ FONTES ARAÚJO ${ }^{5}$, JOSÉ TARCÍSIO LIMA THIÉBAUT ${ }^{6}$, MÁRCIA TEREZINHA RAMOS DE OLIVEIRA7
}

\begin{abstract}
RESUMO - A literatura apresenta resultados conflitantes sobre a manutenção do potencial fisiológico de semente de mamão armazenada por longos períodos com baixo teor de água e em ambientes a baixas temperaturas. Neste trabalho, sementes de mamão do cultivar UENF-CALIMAN 01 foram secadas à sombra até teor de água de $12,6 \%$ b.u. e submetidas à secagem complementar a $37^{\circ} \mathrm{C}$, em secador de bandejas, até atingir teor de água de 7,7\% b.u. A germinação e o vigor da semente, estimado pela contagem de plântulas normais fortes aos 14 dias, foram avaliados depois de submetidos aos dois processos de secagem e aos quatro e oito meses de armazenamento, em embalagem hermética a $15^{\circ} \mathrm{C}$. O vigor da semente, inicialmente de cerca de $46 \%$, aumentou para $77 \%$, depois de quatro meses de armazenamento. O percentual de germinação, depois dos processos de secagem, foi de $75 \%$, aumentando para $87 \%$ e declinando para $66 \%$, aos quatro e oito meses de armazenamento, respectivamente. Os resultados obtidos no presente trabalho indicam que o comportamento da semente de mamão se aproxima mais daquele observado em sementes ortodoxas, que têm sua viabilidade extendida pela redução simultânea do teor de água e da temperatura, durante o armazenamento.
\end{abstract}

Termos para indexação: sementes de mamão, secagem, armazenamento, qualidade fisiológica.

\author{
PHYSIOLOGICAL QUALITY OF PAPAYA SEEDS AS AFFECTED BY DRYING AND \\ STORAGE
}

\begin{abstract}
Conflicting results are reported in the literature concerning the germination capability of papaya seeds submmitted to long-term storage at low moisture content and temperature levels. This study was undertaken to evaluate the viability of papaya seeds of the UENF-CALIMAN 01 cultivar dried under shade to $12.6 \%$ w.b moisture and subsequently dried at $37{ }^{\circ} \mathrm{C}$ in a cabinet drier to $7.7 \%$ w.b. The germination and vigour of these seeds were evaluated after drying and after four and eight months of storage in a sealed, moistureproof container at $15{ }^{\circ} \mathrm{C}$. Seed vigour, initially of $46 \%$, increased to $77 \%$ after four months of storage. Seed germination after drying to the two moisture levels was $75 \%$, increasing to $87 \%$ and declining to $66 \%$ after four and eight months of storage, respectively. Results indicated that papaya seeds exhibit signs that prompt their classification as orthodox seeds, which are capable of extending their viability by the simultaneous reduction of mositure content and temperature during storage.
\end{abstract}

Index terms: papaya seeds, drying, storage, physiological quality.

${ }^{1}$ Submetido em 28/01/2007. Aceito para publicação em 17/09/2007.

${ }^{2}$ Professor Associado, Ph.D., bolsista CNPq, Laboratório de Engenharia Agrícola (LEAG), Universidade Estadual do Norte Fluminense Darcy Ribeiro (UENF), CEP 28013-602 Campos dos Goytacazes, RJ. pberbert@uenf.br

${ }^{3}$ Eng Agrônomo, M.S., Doutorando do Programa de Pós-Graduação em Produção Vegetal da UENF. carlesso@uenf.br
${ }^{4}$ Professor Titular, Ph.D., Laboratório de Fitotecnia (LFIT), UENF. roberto@uenf.br ${ }^{5}$ Professor Adjunto, D.S., Departamento de Fitotecnia, UFV, CEP 36571-000 Viçosa, MG. efaraujo@ufv.br

'Professor Associado, D.S., LEAG/UENF.jtt1512@uenf.br

${ }^{7}$ Tecnóloga em Horticultura, Mestranda do Programa de Pós-Graduação em Produção Vegetal da UENF. maroli@uenf.br 


\section{INTRODUÇÃO}

A principal forma de multiplicação da cultura do mamoeiro utilizada pelos produtores brasileiros é a sexuada. Apesar de o mamoeiro poder ser propagado vegetativamente por enxertia, estaquia ou por cultura in vitro de tecidos, apenas a multiplicação seminífera apresenta resultados, técnica e economicamente, satisfatórios (Oliveira e Trindade, 2000).

Os primeiros trabalhos publicados sobre a qualidade fisiológica de semente de mamão relatavam que a germinação era lenta e errática, mesmo nos casos em que a sarcotesta, onde há substâncias inibidoras de crescimento, havia sido removida (Lange, 1961; Ramirez, 1961). Com o passar dos anos, observa-se, no entanto, que os resultados sobre os percentuais de germinação e vigor dessa semente encontrados na literatura continuam a ser conflitantes e geralmente dizem respeito ao efeito de fatores tais como estágio de maturação dos frutos (Lima-Díaz et al., 1985), tipo de secagem (Vecchio e Shirwa, 1987), remoção da sarcotesta (Pérez et al., 1980; Schmildt et al., 1993), utilização de ácido giberélico e tamanho da semente e sua posição no fruto (Nagao e Furutani, 1986) e condições de armazenamento (Santos et al, 1999; Viggiano et al., 2000). Os trabalhos acima mencionados relatam percentuais de germinação entre $12 \%$ e $90 \%$, dependendo do tratamento empregado.

Além desses fatores, a própria classificação da semente de mamão, de acordo com sua sensibilidade à dessecação, ainda suscita dúvidas, pois a literatura apresenta resultados indicando a conservação do seu potencial fisiológico sob ampla variação do teor de água, além de suportar dessecação mais severa que inúmeras recalcitrantes típicas (Marcos Filho, 2005). Ellis et al. (1991) classificaramnas como intermediárias, ao verificarem que quanto mais secas e resfriadas, menor o seu poder germinativo. Althoff e Carmona (1999) não as classificaram, mas observaram que não houve perdas sensíveis de viabilidade, em função da secagem até teores de água em torno de $5 \%$ b.u., não se mostrando, no entanto, resistentes a baixas temperaturas $\left(5^{\circ}\right.$ C). Sun e Liang (2001) não as classificaram como ortodoxas; afirmaram, no entanto, que não deveriam ser classificadas como recalcitrantes ou intermediárias.

Observa-se, portanto, que são poucas as informações disponíveis na literatura sobre a secagem artificial da semente de mamão que contenham indicações precisas das propriedades psicrométricas do ar utilizado no processo. Os trabalhos publicados relatam experimentos de secagem geralmente realizados à sombra ou pleno sol ou em estufa, situações em que há pouco ou nenhum controle de parâmetros relevantes como temperatura, razão da mistura do ar de secagem e fluxo de ar seco.

A secagem de semente, apesar de ser uma das etapas cruciais na cadeia produtiva de alimentos, continua a ser um de seus elos mais negligenciados. Estima-se que até $60 \%$ da energia necessária para a produção de cereais seja utilizada na etapa de secagem (Brooker et al., 1992). No entanto, sua importância não reside apenas no fato de ser a operação que mais demanda energia na seqüência produtiva que se inicia na seleção de progenitores, no beneficiamento da semente, passa pelo preparo do solo, semeadura, tratos culturais, engenharia de irrigação, continua na colheita, manuseio, secagem, armazenamento e transporte. Há um consenso generalizado sobre o fato de a secagem incorreta ser a principal causa da deterioração de semente nessa série de processos (BakkerArkema et al., 1985). Desse modo, se houver negligência na secagem da semente, o esforço despendido em estudos de melhoramento genético, fitotécnicos e zoneamento edafoclimático poderá ser comprometido.

No caso específico da produção de semente de mamão, o prejuízo financeiro que uma secagem inadequada pode causar pode ser facilmente verificado. $\mathrm{O}$ presente trabalho trata da secagem de um lote de cerca de $150 \mathrm{~kg}$ de sementes de mamão, cujo valor de mercado encontra-se em torno de US\$ $4.000,00 / \mathrm{kg}$; portanto, a perda de viabilidade dessa semente, devido à secagem mal realizada, poderia acarretar prejuízo da ordem de US\$ $600.000,00$. O objetivo deste trabalho foi avaliar os efeitos da secagem e do armazenamento no vigor e na germinação de semente de mamão (Carica papaya L.) do híbrido UENF-CALIMAN 01.

\section{MATERIAL E MÉTODOS}

A semente de mamão (Carica papaya L.) do híbrido UENF-CALIMAN 01 utilizada neste trabalho, obtida do cruzamento entre progenitores dos Grupos Formosa e Solo, foi fornecida pela empresa Caliman Agrícola S/A, sendo proveniente de pomar instalado na fazenda Macuco, localizada no município de Linhares, ES. Os frutos foram colhidos no estádio de maturação 1, quando estavam mudando de cor, apresentando os primeiros sinais amarelos, que não cobriam mais de $15 \%$ da casca. Os frutos foram então armazenados em condições ambientes por quatro dias e a extração de semente ocorreu quando encontravamse no estádio de maturação 5 , ou seja, maduros e com $75 \%$ a $100 \%$ da superfície da casca amarelada. Depois de extraídas dos frutos, as sementes permaneceram imersas em água por $24 \mathrm{~h}$, passando em seguida por lavagem em água 
corrente sobre peneira de malha metálica, para retirada dos tecidos placentários e de parte da polpa, sendo em seguida submetidas ao processo de retirada da sarcotesta, o qual consistiu em friccioná-las manualmente contra a malha da peneira, também sob jato de água. Posteriormente, foram secadas à sombra em secador de telas suspensas, até teor de água médio de $12,6 \%$ b.u. Ao final da secagem, as sementes foram acondicionadas em sacos de papel com capacidade para cerca de $2 \mathrm{~kg}$ e armazenadas em câmara climática a $10^{\circ} \mathrm{C}$, por 15 dias. Posteriormente, as sementes foram retiradas das embalagens onde se encontravam originalmente e colocadas em sacos pretos de polietileno com capacidade para $15 \mathrm{~kg}$, perfazendo um total de 10 sublotes. As sementes foram então colocadas em caminhão com compartimento frigorificado e transportadas para a UBS do Departamento de Fitotecnia da Universidade Federal de Viçosa, Viçosa, MG. Depois de beneficiadas, foram levadas para secagem complementar no Centro Nacional de Treinamento em Armazenagem CENTREINAR, Departamento de Engenharia Agrícola DEA/UFV.

A secagem complementar foi realizada em secador do tipo cabine, de quatro compartimentos com bandejas, fabricado pela Polidryer Comércio e Indústria de Máquinas Ltda, Viçosa, MG. O secador utilizado possui duas câmaras de secagem adjacentes, com seção transversal unitária de 0,2 $\mathrm{m}^{2}$, capacidade estática para $15 \mathrm{~kg}$ de sementes e altura de 2,0 m, o que o caracteriza como secador vertical (Figura 1a). Cada um dos quatro compartimentos de secagem contém 15 bandejas com fundo perfurado em malha de aço galvanizado (Figura $1 b$ ) e com capacidade média para $0,25 \mathrm{~kg}$, permitindo a secagem de cerca de $3,75 \mathrm{~kg}$ de semente por seção. Cada uma das câmaras é dividida em dois compartimentos separados por plenum (Figuras 2a e 2b); desse modo, o fluxo de ar é ascendente nos dois compartimentos superiores e descendente nos dois inferiores. $\mathrm{O}$ aquecimento do ar de secagem foi realizado por intermédio da queima de gás liquefeito de petróleo (propano, $\mathrm{C}_{3} \mathrm{H}_{8}$ ). O consumo específico de energia ( $\mathrm{kJ} . \mathrm{kg}^{-1}$ de água evaporada) foi calculado por meio da seguinte equação: $\mathrm{E}=$ [PCI.c. $\left.\left(100-\mathrm{U}_{\mathrm{f}}\right)\right] /\left[\mathrm{M} .\left(\mathrm{U}_{\mathrm{i}}-\right.\right.$ $\left.\mathrm{U}_{\mathrm{f}}\right)$ ], em que $\mathrm{c}=$ consumo total de gás, $\mathrm{kg} \mathrm{M}=$ massa inicial do produto, $\mathrm{kg}_{\mathrm{i}}=$ teor de água inicial, \% b.u. e $\mathrm{U}_{\mathrm{f}}=$ teor de água final, \% b.u. (Freire, 1998). Para o cálculo do valor de E, considerou-se poder calorífico inferior (PCI) de 46,4 MJ . $\mathrm{kg}^{-1}$ (van Wylen e Sonntag, 1976). O consumo de gás foi medido por diferença de massa.

Os testes adicionais de secagem foram realizados empregando apenas um nível de temperatura e vazão específica do ar de secagem, $37^{\circ} \mathrm{C}$ e $0,7 \mathrm{~m}^{3} \cdot \mathrm{min}^{-1} \cdot \mathrm{m}^{-2}$, respectivamente. A velocidade do ar foi medida com o auxílio de anemômetro modelo PVM fabricado pela Dwyer Instruments Inc. As leituras de velocidade e temperatura do ar de secagem foram registradas antes de se retirar as bandejas, em cada procedimento de pesagem. A temperatura e a umidade relativa do ar ambiente foram registradas utilizando termohigrógrafo SATO Sigma II, Modelo NSII-Q, para avaliar as propriedades psicrométricas do ar de secagem, como entalpia, razão da mistura e volume específico ( Melo et al. 2004).

Antes de proceder à secagem de cada sublote, foram retiradas amostras de semente, sendo parte dela utilizada para a determinação do teor de água inicial e a outra para a realização dos testes de avaliação da qualidade fisiológica. No início de cada teste experimental, as sementes de um mesmo sublote, em equilíbrio térmico com o ar ambiente,
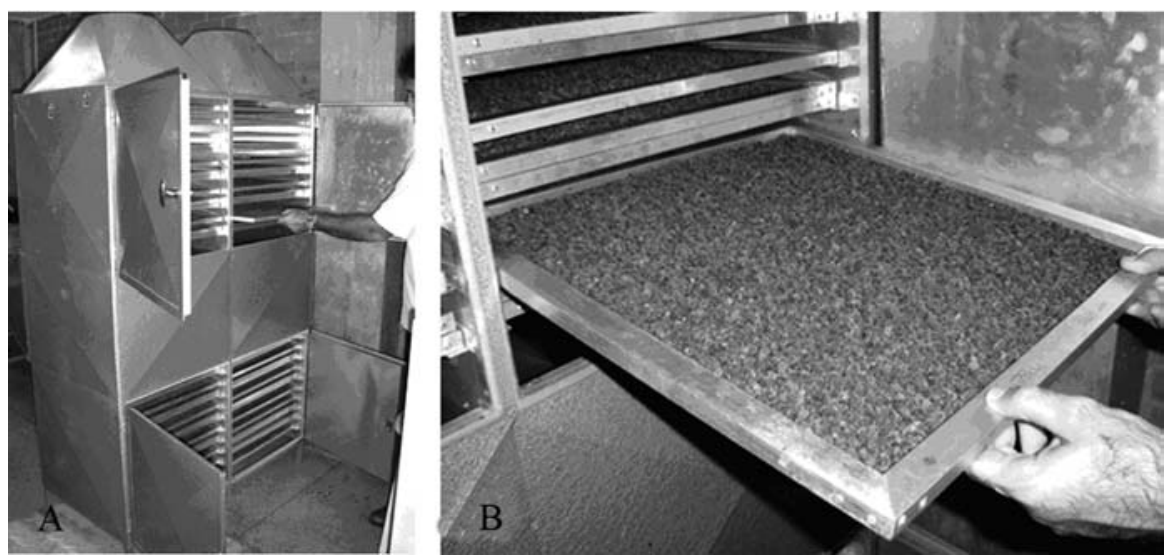

Figura 1. (a) Secador de amostras de semente com as quatro câmaras de secagem; (b) Bandeja do secador com sementes de mamão. 

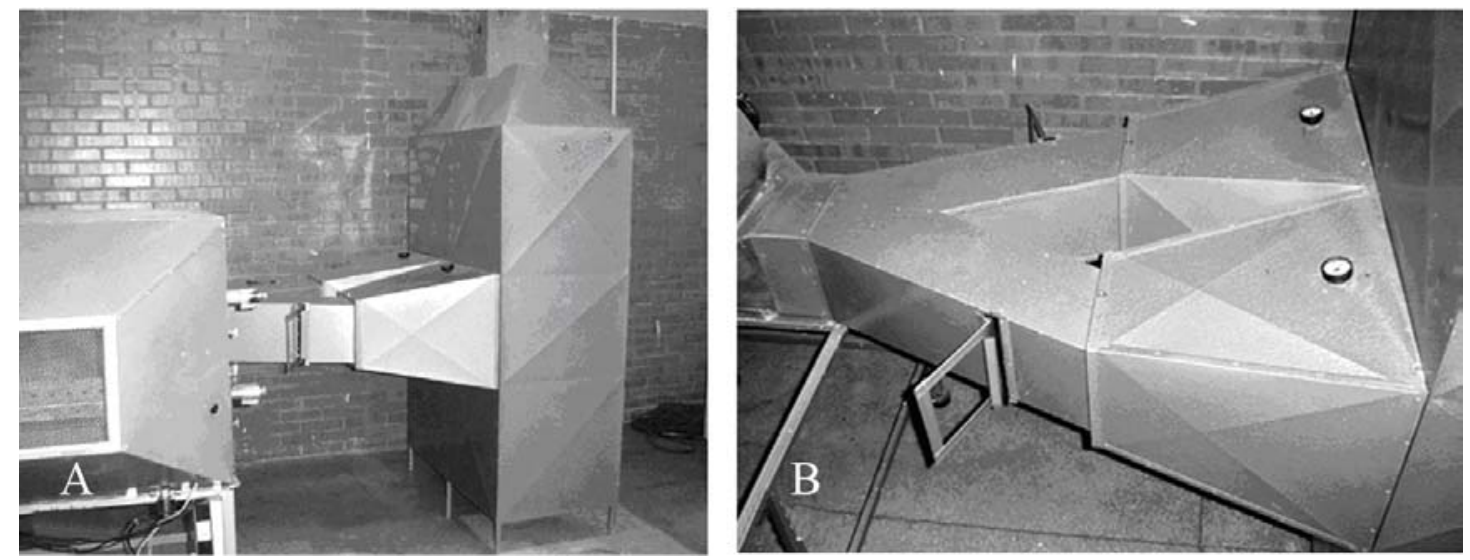

Figura 2. (a) Câmaras do secador (à direita) e câmara de combustão (à esquerda); (b) Bifurcação da tubulação de passagem do ar; expansão para redução da turbulência e a posição de entrada do ar nas duas câmaras plenum.

foram colocadas em camadas finas com altura correspondente à espessura média de duas sementes. Procedimento semelhante de amostragem foi adotado depois da secagem, com o intuito de determinar o teor de água final. Portanto, o poder germinativo e o vigor da semente foi avaliado logo depois de terminada a secagem, para determinação do seu efeito imediato sobre a germinação, e, depois de quatro e oito meses de armazenamento, para verificação do seu efeito latente.

A amostra de semente destinada à avaliação da qualidade fisiológica foi subdividida em duas porções com aproximadamente a mesma massa, sendo acondicionadas em frascos de vidro de $150 \mathrm{~mL}$, com tampa rosqueável e vedados com Parafilm ${ }^{\circledR}$ e armazenadas em câmara do tipo B.O.D. à $15^{\circ} \pm 1^{\circ} \mathrm{C}$. Essas amostras foram utilizadas para realização dos testes de avaliação da qualidade fisiológica das semente, em função do período de armazenamento, ou seja, aos quatro e oito meses.

O teor de água foi determinado de acordo Brasil (1992), utilizando, no entanto, estufa com circulação forçada de ar a $130^{\circ} \pm 1^{\circ} \mathrm{C}$, por uma hora. Durante o processo de secagem, a determinação do teor de água foi por gravimetria, utilizando balança semi-analítica Sartorius modelo BP $4100 \mathrm{~S}$, com monitoramente da perda de massa da semente .

Para minimizar o gradiente de umidade, foi alternada a posição das bandejas, a cada intervalo de uma hora.. A secagem foi interrompida quando o teor de água do produto atingiu o valor de cerca de $8 \%$ b.u.

Terminados os testes experimentais de secagem e depois de parcialmente resfriadas, as sementes eram então colocadas novamente nos sacos plásticos em que foram transportadas da Caliman Agrícola S/A para a UFV, permanecendo por no mínimo seis horas no Laboratório onde foi feita a secagem. As sementes foram, então, transportadas para câmara climática e armazenadas a $10^{\circ} \mathrm{C}$ e $70 \%$ de umidade relativa, mesmas condições em que haviam permanecido armazenadas na UBS de origem.

A qualidade fisiológica foi avaliada mediante teste de vigor, estimado pela contagem de plântulas normais fortes aos 14 dias e teste padrão de germinação, estimado pela contagem de plântulas normais aos 28 dias (Brasil, 1992) e foi realizada no Laboratório de Engenharia Agrícola (LEAG) do Centro de Ciências e Tecnologias Agropecuárias (CCTA), Universidade Estadual do Norte Fluminense Darcy Ribeiro (UENF), Campos dos Goytacazes, RJ. Foram classificadas como plântulas normais fortes as que se apresentavam vigorosas, com parte aérea e sistema radicular bem desenvolvidos e tamanho do hipocótilo igual ou superior a $2,5 \mathrm{~cm}$.

Os resultados foram analisados, considerando o método de Amostragem Simples ao Acaso (Cochran, 1977). As amostras foram dimensionadas considerando $\alpha=5 \%$ e d $=10 \%$ em torno da média. Os intervalos de confiança para proporção e porcentagem foram obtidos com probabilidade de $95 \%$. Nesse sentido, os valores de germinação e o vigor de todos os sublotes foram avaliados conjuntamente, para cada uma das dez situações estudadas, ou seja, a qualidade fisiológica da semente, antes e imediatamente depois da secagem complementar e aos quatro e oito meses de armazenamento, com dois teores de água. Os valores de vigor e germinação foram analisados usando o aplicativo computacional Sistemas para Análises Estatísticas - SAEG 9.0. 


\section{RESULTADOS E DISCUSSÃO}

A temperatura do ar de secagem foi de $36,5^{\circ} \pm 0,9^{\circ} \mathrm{C}$ e a vazão específica foi de $0,7 \pm 0,1 \mathrm{~m}^{3} \cdot \min ^{-1} \cdot \mathrm{m}^{-2}$. Todos os testes foram realizados em ambiente com temperatura de $17,7^{\circ} \pm 2,2^{\circ} \mathrm{C}$ e umidade relativa de $65,1 \% \pm 4,1 \%$, o que corresponde à razão da mistura de $0,008 \pm 0,001 \mathrm{~kg} \cdot \mathrm{kg}^{-1}$. Essas condições permitiram que o teor de água da semente fosse reduzido de $12,6 \% \pm 1,8 \%$ b.u. para $7,7 \% \pm 1,1 \%$ b.u., em 5,0 $\pm 0,5$ horas. A massa de impurezas e sementes leves foi de $0,580 \mathrm{~kg}$, ou seja, $0,4 \%$ da massa total inicial. Verificou- se que o secador, para as condições testadas, possibilitou a retirada de $1,0 \pm 0,3$ pontos percentuais de água por hora, com consumo específico de energia de 90,9 $\pm 20,3 \mathrm{MJ}$ por quilo de água evaporada, resultando em gradiente final de 1,9 $\pm 0,6$ pontos percentuais de água.

Apresenta-se, na Tabela 1, o resumo das condições psicrométricas do ar ambiente, das condições inicial e final da semente e o tempo de secagem, para todos os testes realizados. Os valores referentes ao consumo de gás, quantidade de água removida, velocidade e vazão específica do ar de secagem encontram-se na Tabela 2.

Tabela 1. Condições médias do ar ambiente, teores de água inicial e final das sementes de mamão e tempo de secagem para todos os sublotes.

\begin{tabular}{|c|c|c|c|c|c|c|}
\hline $\begin{array}{l}\text { Identificação } \\
\text { do sublote }\end{array}$ & $\begin{array}{c}\text { Temperatura } \\
\text { ambiente }\left({ }^{\circ} \mathrm{C}\right)\end{array}$ & $\begin{array}{l}\text { Umidade } \\
\text { relativa (\%) }\end{array}$ & $\begin{array}{c}\text { Razão da } \\
\text { mistura } \\
\left(\mathrm{kg} \cdot \mathrm{kg}^{-1}\right)\end{array}$ & $\begin{array}{c}\text { Teor água } \\
\text { inicial } \\
\text { (\% b.u.) }\end{array}$ & $\begin{array}{c}\text { Teor água } \\
\text { final } \\
\text { (\% b.u.) }\end{array}$ & $\begin{array}{c}\text { Tempo de } \\
\text { secagem } \\
\text { (h) }\end{array}$ \\
\hline 1 & $20,1 \pm 1,4$ & $60,6 \pm 7,8$ & 0,0090 & $13,5 \pm 1,4$ & $7,9 \pm 0,7$ & 5,33 \\
\hline 2 & $18,2 \pm 0,3$ & $62,5 \pm 1,3$ & 0,0082 & $13,6 \pm 0,6$ & $7,7 \pm 0,8$ & 4,28 \\
\hline 3 & $20,3 \pm 1,0$ & $59,4 \pm 1,9$ & 0,0089 & $13,3 \pm 1,8$ & $6,6 \pm 1,4$ & 4,07 \\
\hline 4 & $16,4 \pm 1,0$ & $61,6 \pm 3,6$ & 0,0072 & $11,3 \pm 0,8$ & $7,1 \pm 1,2$ & 5,58 \\
\hline 5 & $18,0 \pm 0,5$ & $65,5 \pm 1,5$ & 0,0085 & $13,8 \pm 0,7$ & $7,1 \pm 1,4$ & 5,33 \\
\hline 6 & $18,3 \pm 0,6$ & $67,2 \pm 1,3$ & 0,0089 & $13,2 \pm 1,8$ & $7,8 \pm 1,3$ & 5,42 \\
\hline 7 & $14,2 \pm 2,7$ & $71,0 \pm 1,7$ & 0,0073 & $13,4 \pm 0,9$ & $7,9 \pm 2,4$ & 4,97 \\
\hline 8 & $13,5 \pm 1,5$ & $72,5 \pm 1,4$ & 0,0070 & $11,8 \pm 0,5$ & $7,8 \pm 1,8$ & 4,83 \\
\hline 9 & $18,6 \pm 0,4$ & $66,4 \pm 1,3$ & 0,0090 & $13,1 \pm 1,0$ & $7,5 \pm 1,5$ & 5,08 \\
\hline 10 & $19,0 \pm 0,3$ & $64,0 \pm 0,9$ & 0,0089 & $13,8 \pm 0,5$ & $7,6 \pm 0,6$ & 5,00 \\
\hline
\end{tabular}

Tabela 2. Quantidade de água removida, consumo de gás, temperatura de secagem, velocidade e vazão específica do ar de secagem para todos os sublotes.

\begin{tabular}{cccccc}
\hline $\begin{array}{c}\text { Identificação } \\
\text { do sublote }\end{array}$ & $\begin{array}{c}\text { Pontos percentuais } \\
\text { de água retirada }\end{array}$ & $\begin{array}{c}\text { Temperatura } \\
\text { de secagem }\left({ }^{\circ} \mathrm{C}\right)\end{array}$ & $\begin{array}{c}\text { Consumo } \\
\text { de gás }(\mathrm{kg})\end{array}$ & $\begin{array}{c}\text { Velocidade } \\
\left(\mathrm{m} \cdot \mathrm{min}^{-1}\right)\end{array}$ & $\begin{array}{c}\text { Vazão específica } \\
\left(\mathrm{m}^{3} \cdot \mathrm{min}^{-1} \cdot \mathrm{m}^{-2}\right)\end{array}$ \\
\hline 1 & 5,6 & $34,8 \pm 1,4$ & 1,9 & 0,69 & $0,7 \pm 0,1$ \\
2 & 5,9 & $35,7 \pm 0,8$ & 1,9 & 0,69 & $0,7 \pm 0,1$ \\
3 & 6,7 & $37,8 \pm 0,9$ & 1,9 & 0,69 & $0,7 \pm 0,1$ \\
4 & 4,2 & $36,6 \pm 0,8$ & 1,9 & 0,69 & $0,7 \pm 0,1$ \\
5 & 6,7 & $36,9 \pm 0,3$ & 2,1 & 0,69 & $0,7 \pm 0,1$ \\
6 & 5,4 & $36,8 \pm 1,9$ & 2,1 & 0,69 & $0,7 \pm 0,1$ \\
7 & 5,5 & $36,0 \pm 0,9$ & 1,9 & 0,68 & $0,7 \pm 0,1$ \\
8 & 4,0 & $36,1 \pm 0,6$ & 2,0 & 0,68 & $0,7 \pm 0,1$ \\
9 & 5,6 & $37,6 \pm 1,0$ & 1,7 & 0,71 & $0,7 \pm 0,1$ \\
10 & 6,2 & $36,6 \pm 0,7$ & 1,5 & 0,68 & $0,7 \pm 0,1$ \\
\hline
\end{tabular}


Os valores dos desvios-padrão dos teores de umidade inicial e final apresentados na Tabela 1 permitem concluir que a ação conjunta do método de secagem e do tipo de secador utilizado resultou em valores elevados para o gradiente final de umidade $(1,9 \pm 0,6$ pontos percentuais de teor de água). Esse tipo de resultado desfavorável pode ser evitado, modificando o projeto do secador ou diminuindo o intervalo de tempo entre as alterações das posição das bandejas. Apresentam-se, na Figura 3, as curvas de secagem da semente dos sublotes 8 e 9, que correspondem aos testes em que se obteve os valores máximo $(2,9)$ e mínimo $(1,2)$, respectivamente, do gradiente final de teor de água.

Os resultados dos testes de avaliação do vigor e da germinação de semente, antes e depois da secagem complementar a $37^{\circ} \mathrm{C}$, estão representados na Figura 4. $\mathrm{Na}$ avaliação do efeito imediato da secagem complementar no vigor de semente, nota-se que o processo o influenciou positivamente, ou seja, o vigor das sementes que foram submetidas à secagem $(48,0 \% \pm 2,2 \%)$ foi estatisticamente superior ao daquelas que não o foram $(43,4 \% \pm 2,2 \%)$. Os resultados referentes ao efeito latente da secagem na qualidade fisiológica de semente, depois de quatro meses de armazenamento, podem ser verificados na Figura 5. O vigor das sementes armazenadas a $12,6 \%$ e $7,7 \%$ b.u. foi de $76,4 \% \pm 1,9 \%$ e $76,6 \% \pm 1,9 \%$, respectivamente, valores que não diferem entre si. No entanto, esses valores são significativamente maiores do que os observados quando se avaliou o efeito imediato da secagem sobre o vigor (Figura 4), representando um aumento de cerca de $70 \%$. Os resultados obtidos coincidem com os relatados por Viggiano et al. (2000), que observaram aumento significativo do vigor de semente de mamão com teor de água de 7,2\% b.u., depois de dois meses de armazenamento a $10^{\circ} \mathrm{C}$, de cerca de $10 \%$ para cerca de $50 \%$. Esse valor manteve-se constante até quatro meses de armazenamento. No entanto, na observação feita aos oito meses, verificou-se que o vigor havia reduzido para
$40 \%$. No presente trabalho, não avaliou-se o vigor aos oito meses de armazenamento.

Quanto ao efeito imediato da secagem no percentual de germinação (Figura 4), os valores obtidos foram de 76,8\% $\pm 1,9 \%$ para semente com teor de água de $7,7 \%$ b.u. e de $74,3 \% \pm 1,9 \%$ para semente com teor de água de $12,6 \%$, porém, esses valores não diferiram estatisticamente, mostrando que não houve efeito imediato da secagem sobre a germinação. Prado e Sartori (2000) reduziram o teor de água de semente de mamão de $73 \%$ para $10 \%$ b.u., em secador de camada delgada, a $41^{\circ} \mathrm{C}$ e $0,5 \mathrm{~m} \cdot \mathrm{s}^{-1}$, e também não observaram efeito imediato da secagem sobre o percentual de germinação, que variou de $91,0 \% \pm 2,5 \%$ para $88,4 \% \pm$ 3,0\%. Althoff e Carmona (1999) também não observaram perda significativa de viabilidade de semente de mamão que teve seu teor de água reduzido para 4,5\% b.u., em ambiente a $25^{\circ} \mathrm{C}$ e $15 \%$ de umidade relativa. Santos et al. (1999) secaram, à sombra, sementes de frutos de mamão do grupo Solo até teor de água de $7 \%$ b.u e constataram que não houve perda de viabilidade logo depois da secagem; observaram percentual de emergência de plântulas de cerca de $80 \%$. No entanto, Viggiano et al. (2000) relataram diminuição de $44 \%$ para $9 \%$ no percentual de germinação de semente de mamão da cultivar Sunrise Solo, ao reduzir seu teor de água de $21 \%$ para valores entre $7 \%$ e $11 \%$ b.u., em secagem combinada à sombra e ao sol. No entanto, a semente teve aumento significativo de germinação (de $9 \%$ para $62 \%$ ), a partir de dois meses de armazenamento, sugerindo que a secagem poderia ter provocado a indução de dormência nas sementes.

Resultados diferentes dos obtidos no presente trabalho também foram observados por Wood et al. (2000) que, ao reduzirem o teor de água de semente de mamão de $62 \%$ para $6 \%$ b.u., em quatro dias de secagem a $15^{\circ} \mathrm{C}$ e $15 \%$ de umidade relativa, em camada delgada, verificaram redução no percentual de germinação de $80 \%$ para $0 \%$. Ellis et al.
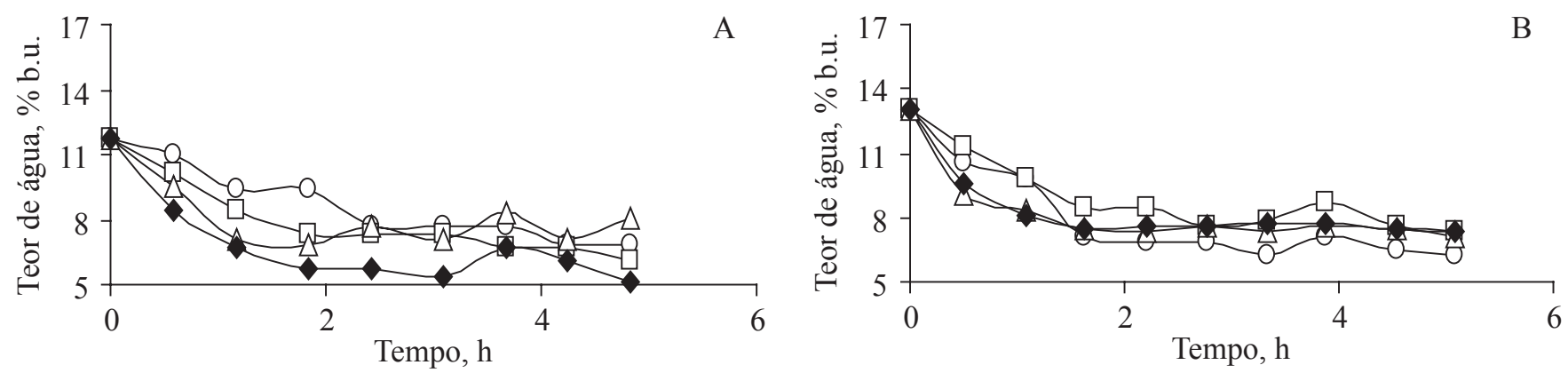

Figura 3. Curvas de secagem da semente dos sublotes 08 (a) e 09 (b). $\triangle$, seção 1; $\bigcirc$, seção 2; $\square$, seção 3 ; •, seção 4. 


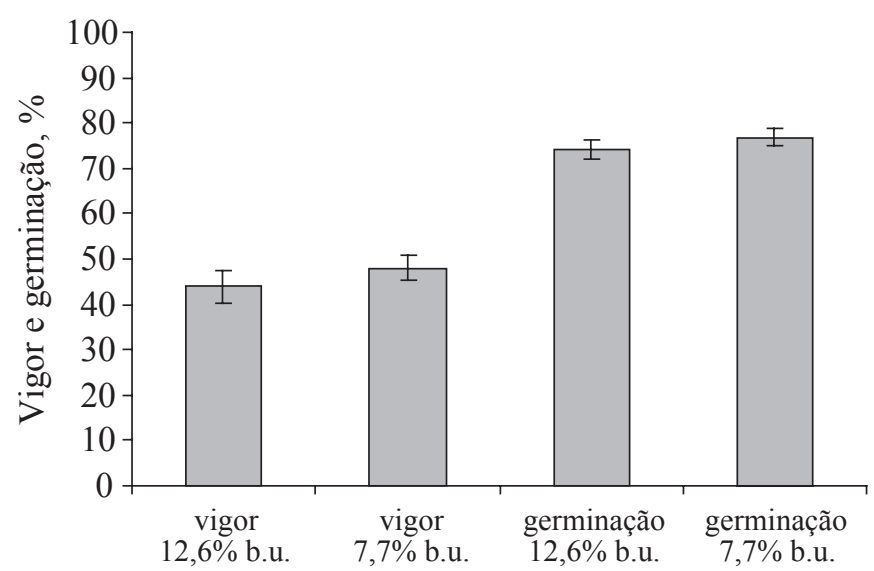

Figura 4. Percentuais de vigor e germinação de semente de mamão do híbrido UENF-CALIMAN 01, obtidos antes $(12,6 \%$ b.u. $)$ e imediatamente depois da secagem $(7,7 \%$ b.u. $)$ complementar a $37^{\circ} \mathrm{C}$.

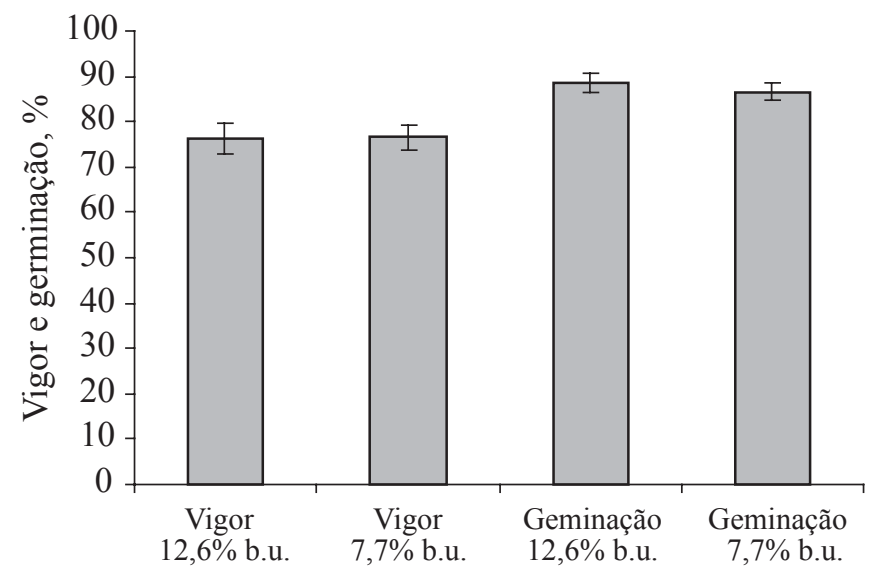

Figura 5. Percentuais de vigor e germinação de semente de mamão do híbrido UENF-CALIMAN 01, obtidos depois de quatro meses de armazenamento a $12,6 \%$ b.u. e $7,7 \%$ b.u.

(1991) também observaram redução sistemática no percentual de germinação, devido à diminuição do teor de água até valores muito reduzidos. Esse fato sugeriria que a semente seria sensível à procedimentos de secagem que provocassem níveis elevados de perda de água. No entanto, Wood et al. (2000) afirmaram que a secagem artificial provocaria apenas dormência temporária em parte das sementes submetidas ao tratamento de secagem, ao invés de reduzir a viabilidade de todo o lote.
Quanto à influência do período de armazenamento no poder germinativo, observa-se que, depois de quatro meses, tanto a semente armazenada a $12,6 \%$ b.u. (sem secagem complementar) quanto aquela armazenada a 7,7\% (com secagem complementar) apresenta percentuais de germinação que não diferem entre si, ou seja, $88,5 \% \pm 1,4 \%$ e $86,6 \% \pm$ $1,5 \%$, respectivamente (Figura 5 ). No entanto, esses valores são significativamente maiores que os observados para a semente que não foi armazenada, ou seja, imediatamente depois da secagem (Figura 4). Os valores correspondentes para oito meses de armazenamento foram de $65,4 \% \pm 2,1 \%$ e $66,8 \% \pm 2,1 \%$, evidenciando queda significativa no poder germinativo, entre quatro e oito meses (Figura 6). Althoff e Carmona (1999) armazenaram semente de mamão com teor de água de $4,5 \%$ b.u. em embalagem impermeável (lata) por 24 meses, em temperatura ambiente, e não observaram alterações sensíveis no poder germinativo. No entanto, verificaram que semente seca de mamão foi sensível ao armazenamento em baixas temperaturas $\left(5^{\circ} \mathrm{C}\right)$. Nessa situação, a perda de viabilidade, no primeiro ano de armazenamento, foi drástica, mantendo-se constante até o final do segundo ano. Santos et al. (1999) não observaram redução significativa na emergência de plântulas de mamão, em função do período de armazenamento da semente. O percentual de emergência de plântulas passou de $80 \%$ para $78 \%$ para semente armazenada por oito meses em temperatura variando entre $2^{\circ}$ e $5^{\circ} \mathrm{C}$; nesse mesmo período, o teor de água da semente diminuiu de $7 \%$ para $6 \%$ b.u. Martins et al. (2005), empregando semente de mamão do grupo Formosa, também observaram aumento do

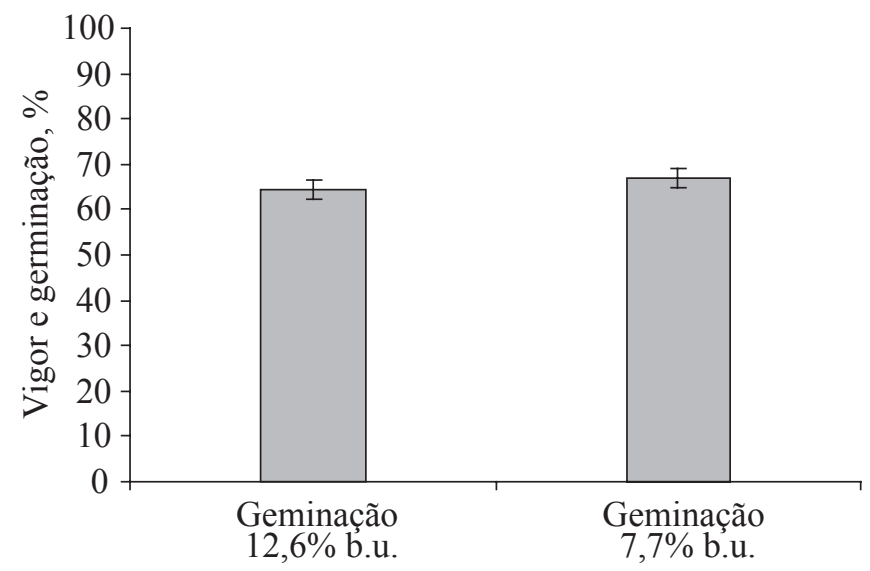

Figura 6. Percentuais de germinação de semente de mamão do híbrido UENF- CALIMAN 01, obtidos depois de oito meses de armazenamento a $12,6 \%$ b.u. e $7,7 \%$ b.u. 
poder germinativo entre zero e três meses de armazenamento e redução entre três e seis meses.

Em relação à classificação da semente de mamão quanto a sua sensibilidade à desidratação, os resultados obtidos no presente trabalho indicam que seu comportamento aproximase mais do observado em sementes ortodoxas típicas (Roberts, 1973), durante o armazenamento. Além dos resultados discutidos anteriormente, os autores também avaliaram a qualidade fisiológica da semente que retornou à Caliman Agrícola S/A, tendo sido acondicionada em latas herméticas com capacidade para $100 \mathrm{~g}$ de sementes e armazenadas a $10^{\circ} \mathrm{C}$, por 12 meses. Essa avaliação adicional mostrou que o vigor e a germinação da semente com teor de água de $8,9 \%$ $\pm 0,2 \%$ b.u. foram de $49,5 \%$ e $85,7 \%$, respectivamente, ou seja, não houve redução da viabilidade da semente seca de mamão, durante o armazenamento em câmara fria por período prolongado. Naturalmente, a manutenção da viabilidade e a classificação da semente de mamão como ortodoxa preconiza que sejam observados diversos aspectos relacionados ao seu pré-processamento, tais como estádio de maturação e período de repouso dos frutos, remoção da sarcotesta e método e taxa de secagem.

Os resultados aqui apresentados diferem dos observados por Ellis et al. (1991), que classificaram a semente de mamão como intermediária, por demonstrar queda da viabilidade quando armazenada a temperaturas abaixo de $15^{\circ} \mathrm{C}$ para teores de água entre $8,0 \%$ e $9,5 \%$ b.u. Althoff e Carmona (1999) obtiveram resultados que diferem das observações de Ellis et al. (1991) ao verificarem que semente de mamão pode ser dessecada até teor de água de $5 \%$ b.u. e armazenada em temperatura ambiente sem perder o poder germinativo. No entanto, mesmo sendo tolerante à dessecação, a semente de mamão não mostra resistência ao armazenamento em baixas temperaturas $\left(5^{\circ} \mathrm{C} \mathrm{e}-18{ }^{\circ} \mathrm{C}\right)$, apresentando perda drástica de viabilidade, depois de um ano de armazenamento. Bass (1975) não observou perda excessiva de viabilidade de semente de mamão armazenada por seis anos em embalagem permeável a $10^{\circ} \mathrm{C}$ e $50 \%$ de umidade relativa ou em embalagem impermeável a $5^{\circ} \mathrm{C}$.

Wood et al. (2000) observaram redução sistemática do poder germinativo de semente de mamão, de $80 \%$ para $0 \%$, em ambiente a $26^{\circ} \mathrm{C}$, depois de ter seu teor de água reduzido de $50 \%$ para $5 \%$ b.u., respectivamente. Esse fato, segundo os autores, poderia sugerir que a semente seria realmente sensível à dessecação. No entanto, a redução do poder germinativo da semente não foi tão drástica, de $75 \%$ para $50 \%$, quando semeada sob regime alternado de temperatura $\left(33^{\circ} / 19^{\circ} \mathrm{C}\right)$. Esses resultados indicam que teria sido a rápida redução do teor de água (de valores iniciais entre $53 \%$ a $62 \%$ b.u. para cerca de $8 \%$ b.u. em apenas um dia de secagem, atingindo o valor final de $5 \%$ b.u. depois de 13 dias em câmara seca) a causa da indução do estado de dormência na semente, ao invés de ter promovido a redução de sua viabilidade por baixa tolerância à dessecação.

Sun e Liang (2001), ao avaliar o grau de sensibilidade à desidratação de semente de diversas espécies classificadas como recalcitrantes e intermediárias, verificaram ser possível sua classificação em níveis discretos de potencial hídrico crítico (PHC). Entretanto, para as espécies cuja semente foi classificada com PHC de $-73 \mathrm{MPa}$, caso da semente de mamão, os valores, na realidade, variaram em um amplo espectro, de -65 a $-90 \mathrm{MPa}$. Os valores correspondentes de umidade relativa para esse intervalo de potencial hídrico variaram entre $54 \%$ e $62 \%$. Em função desse resultado, Sun e Liang (2001) afirmaram que semente de mamão não deve ser classificada como recalcitrante nem como intermediária, de acordo com as categorias clássicas propostas por Roberts (1973) e por Ellis et al. (1990).

\section{CONCLUSÕES}

A secagem complementar da semente de $12,6 \%$ para $7,7 \%$ b.u., a $37^{\circ} \mathrm{C}$, tem efeito imediato positivo sobre o vigor de semente de mamão do híbrido UENF-CALIMAN 01.

O potencial fisiológico da semente de mamão submetida a secagem complementar pode ser aumentado ao longo do armazenamento por quatro meses, sob condições de temperatura de $15^{\circ} \mathrm{C}$

A classificação da semente de mamão, em função de sua tolerância à dessecação, aproxima-se mais da observada para as sementes ortodoxas.

\section{AGRADECIMENTOS}

Os autores agradecem o apoio técnico e financeiro das seguintes instituições: CALIMAN AGRÍCOLA S/A, CENTREINAR, CAPES, CNPq, FAPERJ, FINEP e International Foundation for Science - IFS.

\section{REFERÊNCIAS}

ALTHOFF, M.A.; CARMONA, R. Conservação de sementes de mamão (Carica papaya L. - Caricaceae). Revista Brasileira de Sementes, v.21, n.1, p.151-156, 1999.

BAKKER-ARKEMA, F.W.; BROOK, R.C.; LEREW, L.E. Cereal Grain Drying. In: POMERANZ, Y. (ed.). Advances in Cereal Science and Technology, Volume II. St. Paul: American Association of Cereal Chemists, 1985. p.1-90. 
BASS, L.N. Seed storage of Carica papaya L. HortScience,v.10, n.3, p.232, 1975.

BRASIL. Ministério da Agricultura e Reforma Agrária. Regras para análise de sementes. Brasília: SNDA/DNDV/ CLAV, 1992. 365p.

BROOKER, D.D.; BAKKER-ARKEMA, F.W.; HALL, C.W. Drying and Storage of Grains and Oilsseds. New York: Van Nostrand Reinhold, 1992. 450p.

COCHRAN, W.G. Sampling Techniques. New York: John Wiley \& Sons, Inc. , 1977. 448p.

ELLIS, R.H.; HONG, T.D.; ROBERTS, E.H. An intermediate category of seed storage behaviou? I. Coffee. Journal of Experimental Botany, v.41, n.230, p.1167-1174, 1990.

ELLIS, R.H.; HONG, T.D.; ROBERTS, E.H. Effect of storage temperature and moisture on the germination of papaya seeds. Seed Science Research, v.1, p.69-72. 1991.

FREIRE, A.T. Projeto e avaliação de um sistema para secagem combinada de café( Coffea arabica L.) despolpado. 1998. 76f. Dissertação (Mestrado em Engenharia Agrícola) -Universidade Federal de Viçosa, Viçosa, 1998.

LANGE, A.H. Effect of the sarcotesta on germination of Carica papaya. Botanical Gazette, v.122, n.4, p.305-311, 1961.

LIMA-DÍAZ, S.; LIMA-DÍAZ, I.; VALENZUELAGALINDO, R.; MACIAS, P. Estudio de la viabilidad de la semilla de Carica papaya L. (variedad Maradol Roja). Centro Agrícola, v.12, n.3, p.119-130, 1985.

MARCOS FILHO, J. Fisiologia de sementes de plantas cultivadas. Piracicaba: FEALQ, 2005. 495p.

MARTINS, G.N.; SILVA, R.F.; ARAÚJO, E.F.; PEREIRA, M.G.; VIEIRA, H.D.; VIANA, A.P. Influência do tipo de fruto, peso específico das sementes e período de armazenamento na qualidade fisiológica de sementes de mamão do grupo Formosa. Revista Brasileira de Sementes, v.27, n.2, p.12-17, 2005.

MELO, E.C.; LOPES, D.C.; CORRÊA, P.C. GRAPSI Programa computacional para o cálculo das propriedades psicrométricas do ar. Engenharia na Agricultura, v.12, n.2, p.154-162, 2004.

NAGAO, M.A.; FURUTANI, S.C. Improving germination of papaya seed by density separation, potassium nitrate, and gibberellic acid. HortScience, v.21, n.6, p.1439-1440, 1986.

OLIVEIRA, J.R.P.; TRINDADE, A.V. Propagação e formação do pomar. In: TRINDADE, A.V. (organizador). Mamão. Produção: aspectos técnicos. Brasília: Embrapa Comunicação para Transferência de Tecnologia, 2000. p.20-25.

PÉREZ, A.; REYES, M.N.; CUEVAS, J. Germination of two papaya varieties: effect of seed aeration, K-treatment, removing of the sarcotesta, high temperature, soaking in distilled water and age of seeds. Journal of Agriculture of the University of Puerto Rico, v.64, n.2, p.173-180, 1980.

PRADO, M.M.; SARTORI, D.J.M. Avaliação da secagem convectiva de sementes de papaya com e sem mucilagem. In: CONGRESSO BRASILEIRO DE ENGENHARIA QUÍMICA, 12, Águas de São Pedro, 2000. Anais. São Paulo: SONOPRESS RIMO LTDA, 2000, v.1, p. 54801-54810.

RAMIREZ, O.D. Effect of gibberellic acid on germination of papaya (Carica papaya L.) seed. Journal of Agriculture of the University of Puerto Rico, v.4, n.3, p.188-190, 1961.

ROBERTS, E.H. Predicting the storage life of seeds. Seed Science \& Technology, v.1, p.499-514, 1973.

SANTOS, R.C.A.; SAMPAIO, L.S.V.; COSTA, J.A. Condição ambiental, teor de água e embalagem na viabilidade e no vigor de sementes de mamão. Revista Brasileira de Sementes, v.21, n.2, p.194-202, 1999.

SCHMILDT, E.R.; FRONZA,V.; DIAZ, J.L.S.; UNÊDA, S.H.; ALVARENGA, E.M. Comparação de métodos físicos de remoção da sarcotesta e de métodos de secagem de sementes de mamoeiro (Carica papaya L.). Revista Brasileira de Sementes, v.15, n.2, p.147-151, 1993.

SUN, W.Q.; LIANG, Y. Discrete levels of desiccation sensitivity in various seeds as determined by the equilibrium dehydration method. Seed Science Research, v.11, p.317323, 2001.

van WYLEN, G.J.; SONNTAG, R.E. Fundamentos da Termodinâmica Clássica. São Paulo: Editora Edgard Blücher Ltda, 1976. 565 p.

VECCHIO, V.; SHIRWA, A.H. Effets des différentes modalités de séchage de graines de papaye sur la germination. Rivista di Agricoltura Subtropicale e Tropicale, v.81, n.1-2, p.175-184, 1987.

VIGGIANO, J.R; VIEIRA, H.D.; SILVA, R.F.; ARAÚJO, E.F.; VIANA, A.P. Conservação de sementes de mamão (Carica papaya L.) em função do grau de umidade, tipo de embalagem e ambiente de armazenamento. Revista Brasileira de Sementes, v.22, n.2, p.279-287, 2000.

WOOD, C.B.; PRITCHARD, H.W.; AMRITPHALE, D. Desiccation-induced dormancy in papaya (Carica papaya L.) seeds is alleviated by heat shock. Seed Science Research, v.10, p.135-145, 2000. 